\title{
Observations sur la composition des lipides de quelques levures
}

\author{
par \\ G. MOULIN, P. GALZY
}

Laboratoire de Recherches de la Chaire de Génétique Ecole Nationale Supérieure Agronomique

Centre de Recherches Agronomiques de Montpellier Institut National de la Recherche Agronomique 34060 Montpellier - Cedex (France)

et J. BEZARD

Laboratoire de Physiologie Animale et de la Nutrition Université de Dijon Sciences, Mirande

avec la collaboration technique de Mme M.C. DELACHAMBRE et de Mlle H. BOZE

La production de levures sur lactosérum déprotéiné a pris de l'extension depuis le dépôt d'un brevet par les Fromageries Bel. Les levures obtenues sont relativement riches en acides gras insaturés et particulièrement en acide linoléique. Ces acides gras insaturés sont d'un grand intérêt diététique mais rendent plus difficile la conservation du produit. C'est pourquoi il nous a semblé intéressant d'étudier la teneur et la composition en acides gras des lipides de plusieurs souches de levures, cultivées dans des conditions différentes, afin de pouvoir sélectionner une souche et les conditions permettant d'obtenir la teneur la plus faible en lipides, d'une part, et en acides gras insaturés d'autre part, en particulier d'acide linoléique très oxydable.

\section{I. - MATERIEL ET METHODES}

A) MatéRIEL BIOLOGIQUe

On a utilisé quatre souches de levures. Deux proviennent de collections :

- Kluyveromyces fragilis (Jorgensen) Van der Walt : SG 1.

- Kluyveromyces fragilis (Jorgensen) Van der Walt : CBS 5795.

Les deux autres souches ont été isolées à partir de fromages (Moulin et al., 1973) :

- D1 et OCRV. 
TABLEAU 1

Composition en lipides des cellules de Kluyveromyces fragilis SG 1 sur différents substrats de croissance

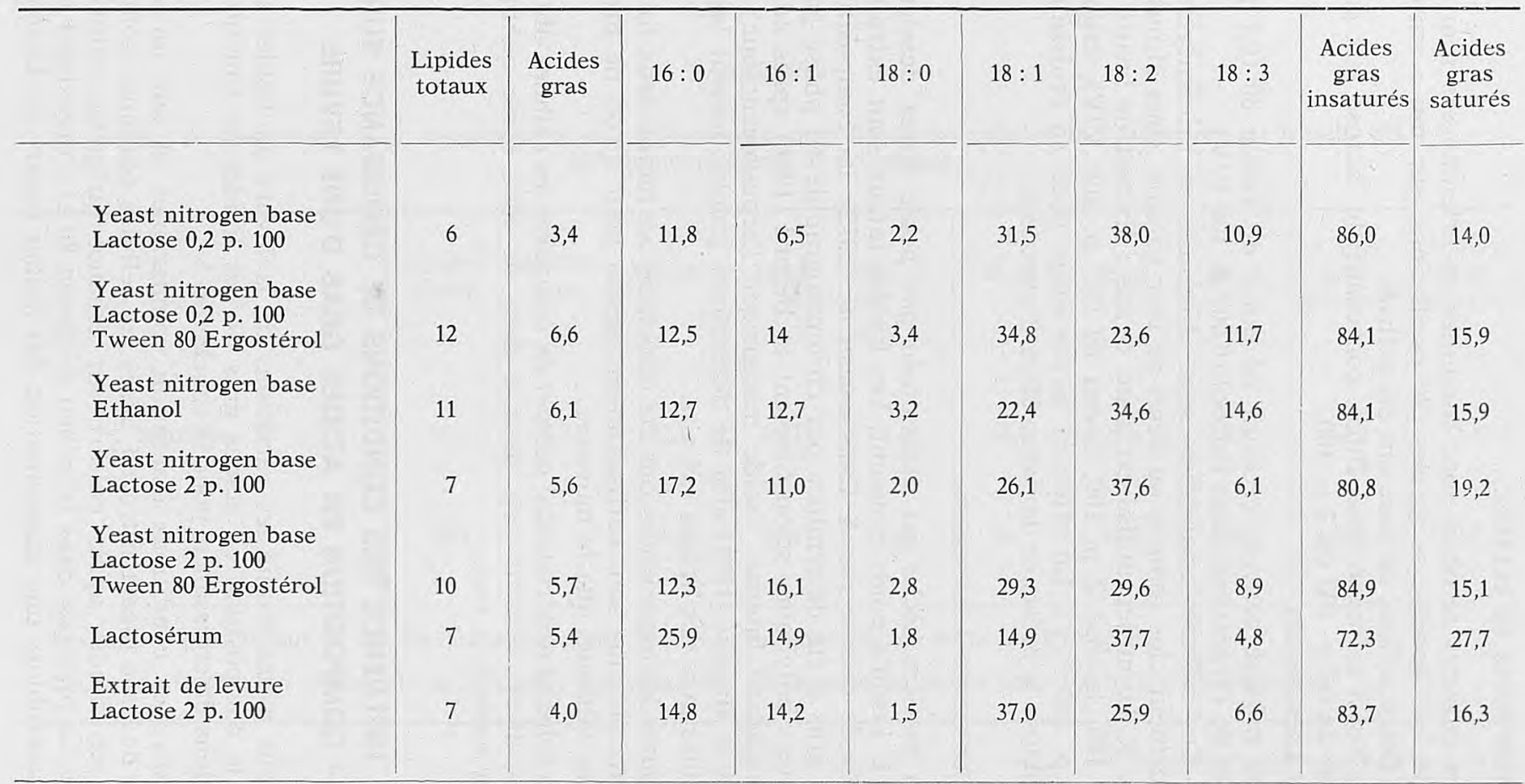

- Les acides gras et les lipides sont exprimés en pourcentage de la matière sèche.

- La concentration en acides gras est exprimée en nombre de mole pour 100 moles d'acides gras. 


\section{B) Techniques de culture}

Les cultures aérobies sont conduites en erlenmeyers remplis au $1 / 10$ de leur volume et agitées ( 80 oscillations par mn ; amplitude $8 \mathrm{~cm}$ ). Deux milieux de base ont été utilisés :

- Yeast nitrogen base Difco, contenant du lactose aux concentrations de 0,2 p. 100 ou 2 p. 100.

- Lactosérum.

Ces milieux peuvent recevoir en outre du tween $80(0,7$ p. 100 $\mathrm{V} / \mathrm{V})$ et de l'ergostérol dans l'alcool (0,007 p. $100 \mathrm{P} / \mathrm{V})$.

- Les cultures anaérobies sont effectuées en erlenmeyers hermétiquement clos remplis au demi de leur volume, sous atmosphère d'azote R. Le milieu utilisé est, dans ce cas : Extrait de levure Difco 0,5 p. 100 , lactose 2 p. 100 , tween $80(0,7$ p. $100 \mathrm{~V} / \mathrm{V})$, ergostérol $(0,007$ p. $100 \mathrm{P} / \mathrm{V})$. En effet, la levure exige pour sa croissance en anaérobiose la présence de tween 80 et d'ergostérol.

\section{C) Techniques analytiques}

La matière sèche est déterminée par pesée après dessiccation à $108^{\circ} \mathrm{C}$ jusqu'à poids constant. Les lipides totaux sont extraits par la méthode décrite par A. CHAssang et al. (1972). La composition en acides gras a été déterminée par chromatographie en phase gazeuse des esters butyliques selon Clément et Bezard (1961) après addition d'un standard interne, l'acide margarique (heptadécanoïque) selon Bezard et Bugaut (1972) afin de déterminer graphiquement le poids des acides gras des lipides extraits.

Toutes les expériences ont été effectuées au moins deux fois. Les résultats obtenus sont suffisamment voisins pour qu'on ne présente dans les tableaux que la moyenne.

Le schéma expérimental permet de comparer les cellules obtenues sur les divers milieux pris deux à deux de telle sorte qu'un seul facteur varie à la fois.

\section{II. - INFLUENCE DES CONDITIONS DE CROISSANCE SUR LA COMPOSITION EN ACIDES GRAS D'UNE LEVURE}

Nous avons étudié les variations de la levure en lipides totaux et de la composition en acides gras de ces lipides en fonction des conditions de croissance, pour la souche SG 1.

Dans des conditions d'aération comparables et sur un même milieu de base (yeast nitrogen base) les cellules obtenues sont plus riches en lipides après culture sur éthanol qu'après culture sur lactose. La présence dans le milieu de tween 80 et d'ergostérol provoque en aérobiose une augmentation des lipides totaux. Le lactosérum 
TABLEAU 2

Action de l'aérobiose et de l'anaérobiose sur la composition en lipide des cellules de Kluyveromyces fragilis SG 1, sur un même milieu de croissance

\begin{tabular}{|c|c|c|c|c|c|c|c|c|c|c|}
\hline & $\begin{array}{l}\text { Lipides } \\
\text { totaux }\end{array}$ & $\begin{array}{l}\text { Acides } \\
\text { gras }\end{array}$ & $16: 0$ & $16: 1$ & $18: 0$ & $18: 1$ & $18: 2$ & $18: 3$ & $\begin{array}{c}\text { Acides } \\
\text { gras } \\
\text { insaturés }\end{array}$ & $\begin{array}{l}\text { Acides } \\
\text { gras } \\
\text { saturés }\end{array}$ \\
\hline Aérobie & 10 & 5,7 & 12,3 & 15,1 & 2,8 & 28,3 & 28,6 & 8,9 & 84,9 & 15,1 \\
\hline Anaérobie & 10,7 & 5 & 11,6 & 18,8 & 0,6 & 50 & 14,9 & 3,9 & 87,6 & 12,4 \\
\hline
\end{tabular}

- Les acides gras totaux et les lipides totaux sont exprimés en pourcentage de la matière sèche.

- La concentration en différents acides gras est exprimée en nombre de moles pour 100 moles d'acides gras. 
est un milieu riche en lactose (3,5 p. 100) et pauvre en lipides ; il donne des résultats comparables au milieu synthétique yeast nitrogen base lactosé à 2 p. 100 . On retrouve dans tous les cas, les mêmes acides gras dans des proportions assez voisines. Toutefois, il faut noter qu'après culture sur lactosérum, l'acide palmitique est anormalement abondant.

Le tableau 2 permet de comparer la teneur en lipides et la composition en acides gras de Kluyveromyces fragilis SG 1, cultivé soit en anaérobiose soit en aérobiose. Les teneurs en lipides et acides gras totaux sont assez voisines. On retrouve dans les deux cas les mêmes acides gras. Par contre, la proportion des divers acides gras insaturés en C 18 varie. En anaérobiose, la levure contient beaucoup plus de $18: 1$ acide oléique et beaucoup moins de $18: 2$ acide linoléique et $18: 3$ acide linolénique, qu'en aérobiose. C'est là un résultat important. Les cellules obtenues en anaérobiose sont certainement moins sensibles à l'oxydation et au rancissement que les cellules obtenues en aérobiose.

Il apparaît nettement que les facteurs qui augmentent la teneur en lipides de la matière sèche sont la présence d'éthanol comme substrat carboné et l'addition dans le milieu d'acide gras (tween 80) et d'ergostérol. Il faut insister également sur le fait que la répartition relative des acides gras est différente en anaérobiose et en aérobiose.

\section{III. - COMPARAISON DE LA TENEUR EN ACIDES GRAS DE DIVERSES SOUCHES DE LEVURES CULTIVEES SUR LACTOSE}

Des différences importantes apparaissent dans la teneur en lipides des différentes souches ( $\mathrm{tab}$. 3). La souche Kluyveromyces fragilis CBS 5795 et la souche $\mathrm{D}_{1}$ qui possèdent des caractères de Kluyveromyces et de Saccharomyces sont nettement plus riches en lipides totaux et en acides gras que les souches Kluyveromyces fragilis SG 1 et OCRV. Rappelons que cette dernière possède des caractéristiques très voisines de Torulopsis candida (Moulin et al., 1973).

La souche SG 1 est nettement moins riche en acides gras que CBS 5795 et $D_{1}$. En outre, elle en diffère par une richesse relative plus grande en 18:0 et par un pourcentage d'acides gras insaturés nettement plus faible. Il en résulte que, pour $100 \mathrm{mg}$ de matière sèche, Kluyveromyces fragilis SG 1 contient seulement $4 \mathrm{mg}$ d'insaturé dont $2 \mathrm{mg}$ de dépolyinsaturé alors que Kluyveromyces fragilis CBS 5795 contient $6 \mathrm{mg}$ d'insaturé dont $3 \mathrm{mg}$ de polyinsaturé. La souche SG 1 présente donc un intérêt industriel dans la mesure où l'objectif recherché est d'obtenir une meilleure conservation du produit. 
TABLEAU 3. - Etude de la composition en lipide de quatre souches cultivées sur lactose 2 p. 100

\begin{tabular}{|c|c|c|c|c|c|c|c|c|c|c|}
\hline & $\begin{array}{l}\text { Acides } \\
\text { gras }\end{array}$ & $\begin{array}{l}\text { Lipides } \\
\text { totaux }\end{array}$ & $16: 0$ & $16: 1$ & $18: 0$ & $18: 1$ & $18: 2$ & $18: 3$ & $\begin{array}{l}\text { Acides } \\
\text { gras } \\
\text { insaturés }\end{array}$ & $\begin{array}{l}\text { Acides } \\
\text { gras } \\
\text { saturés }\end{array}$ \\
\hline $\begin{array}{l}\text { Kluyveromyces fragilis } \\
\text { SG } 1\end{array}$ & 5,6 & 7 & 14,1 & 8,5 & 18,8 & 21,5 & 31,0 & 5,1 & 67,1 & 32,9 \\
\hline $\begin{array}{l}\text { Kluyveromyces fragilis } \\
\text { C.B.S. } 5795\end{array}$ & 6,9 & 10 & 12,2 & 20,3 & 0,9 & 27,6 & 33,1 & 5,9 & 86,9 & 13,1 \\
\hline Souche $D_{1}$ & 10,3 & 13 & 7,1 & 11,4 & 5,2 & 30,5 & 36,0 & 9,8 & 87,7 & 12,3 \\
\hline Souche OCRV & 5,0 & 8 & 17,7 & 1,2 & 6,7 & 55,0 & 17,0 & 5,9 & 75,6 & 24,4 \\
\hline
\end{tabular}

- Les acides gras et les lipides totaux sont exprimés en pourcentage de la matière sèche.

- La concentration en acides gras est exprimée en nombre de mole pour 100 moles d'acide gras. 
La souche OCRV présente plus d'intérêt encore à cet égard. Outre qu'elle contient seulement 5 p. 100 d'acides gras, elle présente un spectre particulièrement intéressant : richesse relative en acide oléique $18: 1$ mais pauvreté en polyinsaturée $18: 2$. Cette souche contient, pour $100 \mathrm{mg}$ de matière sèche, $4 \mathrm{mg}$ d'acides gras insaturés et seulement $1 \mathrm{mg}$ de polyinsaturé.

\section{IV. - CONCLUSION}

Nos observations montrent qu'il est possible de réduire la quantité de lipides dans les cellules de levure en intervenant au niveau des conditions de culture. La composition qualitative en acides gras est constante. En anaérobiose, on observe une teneur plus faible en polyinsaturé qu'en aérobiose.

Des variations importantes existent entre souches. Elles portent sur la teneur en lipides totaux, mais aussi sur les teneurs relatives en divers acides gras. Une souche telle que OCRV présente à cet égard un intérêt évident.

\section{S u m m a ry}

We have studied, the effect of different carbon source, on the fatty acid composition of Kluyveromyces fragilis. The fatty acid compositions of some species of yeast are compared after culture on lactose as sole source of carbon.

\section{Références}

Chassang (A.), Roger (M.), Vezinhet (F.) and Galzy (P.) (1972). - Variation of the lipid content of yeast cells during sporulation. Folia Microbiologica, 17, 241-247.

Clément (G.) et Bezard (J.) (1961). - Technique de dosage par chromatographie gaz-liquide d'un mélange d'acides gras, du butanoïque au docosanoïque. C. R. Acad. Sci. (Paris), 255, 564-566.

BeZARd (J.) and Bugaut (M.) (1972). - The component triglycerides of rat adipase tissue. I. As studied after fractionation into classes by silver ion - thin layer chromatography. J. Chrom. Sci., 10, 451-462.

Moulin (G.), Galzy (P.) et Ferron (F.) (1973). - Etude de quelques souches de levures isolées du fromage. Le Lait, 525-526, 237-245.

Reçu pour publication le 26 juillet 1973. 